\title{
A Study on the Strategic Path of High-quality and Characteristic Independent College Running Based on SWOT Analysis
}

\author{
Xiaoling Yu \\ Department of Scientific Research and College-enterprise \\ Cooperation \\ Lushan College of Guangxi University of Science and \\ Technology \\ Liuzhou, China \\ Xinjian Yang \\ President's Office \\ Lushan College of Guangxi University of Science and \\ Technology \\ Liuzhou, China
}

\author{
Feng Wei* \\ Executive Vice-President \\ Lushan College of Guangxi University of Science and \\ Technology \\ Liuzhou, China \\ Chunyan Wang \\ School of Economics and Management \\ Guangxi University of Science and Technology \\ Liuzhou, China
}

\author{
Tingting Kou \\ President's Office \\ Lushan College of Guangxi University of Science and Technology \\ Liuzhou, China
}

\begin{abstract}
The long-term development of independent colleges lies in their high-quality characteristics. This paper analyzed the internal and external environments related to the development of high-quality characteristics of independent colleges based on SWOT analysis. It proposes five strategic paths for independent colleges' high-quality and characteristic development including clarifying the college-running orientation, improving the model of college governance, offering services for the regional economic and social development, strengthening the cultivation of talents, as well as creating unique college culture, thus building a strategic model of the high-quality and characteristic development for independent colleges.
\end{abstract}

Keywords-SWOT analysis; independent colleges; high-quality characteristics; strategic path

Independent colleges are the product of the innovation of Chinese higher education systems and mechanisms. As an important part of private education, they make a great contribution to the reform and popularization of higher education as well as the economic and social development[1-2] With the popularization of higher education, and the proposition of "realization of the connotative development of higher education" at the 19th CPC National Congress, independent colleges are facing the dual tasks of connotative development and characteristic college-running instead of mere expansion of scale. Therefore, how to realize the high-quality and characteristic development has become a major exploring

Fund Project: Guangxi Education Science “13th Five-Year Plan” 2017 Guangxi Private Education Research Project "Study on the Development of High-quality Characteristics of Guangxi Private Colleges” (Grant No. 2017ZMB004) direction for the future development of many independent colleges.

\section{THE EVOLUTION OF INDEPENDENT COLLEGES}

In September 1999, Wenzheng College of Soochow University and City College of Zhejiang University enrolled students for the first time, which was regarded as the sign of the birth of "private-run second-tier college" [3]. After 2000, a large number of second-tier colleges were successively established across China. In 2003, the number of second-tier colleges reached 360 [4]. In April 2003, the Ministry of Education issued On Standardizing and Strengthening the Management of Independent Colleges Run by Universities in New Mechanisms and Models, officially proposing the term of "independent college". In February 2008, the Ministry of Education issued The Measures for Setup and Management of Independent College, which clarified the nature, rights and interests, establishment requirements of independent colleges and proposed a five-year transitional period of inspection and assessment. In 2014, the State Council issued Decision on Accelerating the Development of Modern Vocational Education, encouraging independent colleges to set their college-running orientation as applied technical colleges and universities when transformed into private colleges and universities. Application-oriented colleges should be an appropriate choice for most independent colleges. By 2018, there were 265 independent colleges, accounting for $10 \%$ among 2631 universities and colleges nationwide and 30\% 
among 747 private colleges and universities. From 2008 to 2018, a total of 64 independent colleges in China were transformed to private colleges and universities, accounting for only $20 \%$ of the total number of independent colleges in China. Those independent colleges enjoy a stable development after the transformation[5].

\section{SWOT ANALYSIS OF HIGH-QUALITY AND} CHARACTERISTIC DEVELOPMENT OF INDEPENDENT COLLEGES

SWOT analysis (alternatively TOWS analysis or TOWS matrix), proposed by Heinz Weihrich, a professor of management at the University of San Francisco in the early 1980s, is often used in corporate strategy-making and competitor analysis. It is intended to help an organization to identify the four factors including strengths, weaknesses, opportunities and threats related to its internal and external environments.

\section{A. Analysis of Strengths}

1) The flexible systems and mechanisms. Independent college, a new type of college-running model, developed under new mechanisms and models in the popularizing process of higher education in China. It has flexible systems and mechanisms, strong independence and innovative development momentum. Its social adjustment ability and market adaptability are relatively stronger than traditional public colleges and universities.

2) The relatively standard education and teaching system. By relying on the resources of their host public universities, independent colleges could establish a mature and standardized education and teaching system in a short time. The shortening of the construction cycle guarantees the quality of education and teaching.

\section{B. Analysis of Weaknesses}

1) The high homogeneity. Independent colleges have great similarities in degree programs, talent cultivation programs and teaching system with their host public universities. Different independent colleges and private colleges and universities also experience the high homogeneity in their degree programs, most of them placing more emphasis on humanity and social disciplines such as management, economy, art and literature. Some engineering colleges emphasize more on non-engineering disciplines and intend to focus more on some certain professional engineering disciplines.

2) The insufficiency of college culture connotation. Due to the short history of development, most of independent colleges are short of scientific research achievements, teaching places, equipment and facilities, book resources, and could not develop a favorable higher education environment and teaching culture. As a result, they are faced with the problems of lack of college culture connotation, poor brand effect and low social recognition.
3) The single financial source. Independent colleges are self-financing institutions with a little national financial support. Tuition is their main financial source. The limited financial source causes the stress in running colleges. At the early stage of their development, in order to increase revenue, independent colleges blindly expanded the enrollment scale, thus leading to the neglect of teaching quality. However, the quality of talent cultivation has an impact on enrollment, and the scale of students will consequently affect revenue. Up to this point, the development of independent colleges enters a vicious circle.

4) The inappropriate faculty structure. At present, the age, education background structure, and professional title structure of independent colleges' faculty are severely polarized. The employment relationship between the independent colleges and the teachers from their host public universities, the re-employed teachers who are retired and part-time teachers is not stable. Besides, the separation rate of full-time teachers is high. Therefore, the stability of faculty resources is poor.

\section{Analysis of Opportunities}

1) The development of era. Driven by major strategies such as national innovation-driven development and Made in China 2025, coping with a new round of scientific and technological revolution and industrial transformation, all sectors of society urgently need a large number of technical talents with modern vocational education background and rich innovative spirit and ability. As the main force of applicationoriented colleges and universities, the birth of independent colleges is inextricably linked with local development. They should actively seek to serve regional economic development and industrial transformation, and build a scientific and rational quality mechanism for talent cultivation to cultivate applied talents with industrial knowledge, practical ability in engineering and competence for industrial development.

2) The deepening of higher education reform. According to the strategic layout of national education plan, by 2020, a group of public colleges and universities will be transformed into applied technical colleges and universities, and undergraduate vocational education will gain a great focus. Policies and measures of enrollment, investment and so on will be inclined to applied technical colleges and universities. In 2019, National Vocational Education Reform Implementation Plan proposed that the high-level applied talent cultivating system should be improved. The qualified public colleges and universities will be transformed into the applied colleges and universities, and the undergraduate vocational education will be carried out. At the same time, the Ministry of Education has further clarified the need to accelerate the transformation of independent colleges and standardize the operation of independent colleges.

3) The inherent requirements of regional economic development. The development of regional economy and society requires a large amount of intellectual support. 
However, most regional economic cities, especially the smallsized and medium-sized cities, are less attractive to talents. With the function of cultivating and retaining talents, colleges have become the main source of talents for regional economic and social development. In order to attract independent colleges to settle in cities, some prefecture-level and countylevel cities in the eastern regions, particularly in Zhejiang and Jiangsu province, offer a series of support of land, taxation, talent introduction and so on [6]. Especially in recent years, the competition for talent introduction has become increasingly fierce, and local governments provide local colleges with increasing support.

\section{Analysis of Threats}

1) Great pressure from the competition for college student source. Faced with current limited student resources market and diversified college-running modes, the competition for college student source is increasingly fierce [7].

2) Shortage of internal motivation for connotation development. Independent colleges face the dual tasks of scale expansion and quality improvement. The key to the connotative development of college is talents. In virtue of insufficient faculty resources or irrational faculty structure, connotative development of independent colleges obviously lacks internal impetus.

\section{The STRATEgIC PATH OF High-QUALITY AND} CHARACTERISTIC DEVELOPMENT OF INDEPENDENT COLLEGE

\section{A. Clarifying the College-running Orientation}

Decision on Accelerating the Development of Modern Vocational Education issued in 2014, encouraged independent colleges to set their college-running orientation as applied technical colleges and universities when transformed into private universities and colleges. Meanwhile, a higher education institutions classification system should be established to implement classified management. Policies and measures of enrollment, investment and so on are inclined to applied technical colleges and universities. National Vocational Education Reform Implementation Plan issued by the State Council in 2019 clearly emphasized that independent colleges should develop into application-oriented colleges and universities. If independent colleges want to achieve highquality development with their own characteristics, they must adapt to the development trend of higher education at first, and then clearly and firmly position themselves as applicationoriented colleges. According to the statistics, all the existing eight independent colleges in Guangxi Zhuang Autonomous Region positioned themselves as application-oriented colleges and universities when they formulated their positioning plans. For example, the orientation of Xiangsihu College of Guangxi University for Nationalities is to become "a regionally advanced and distinctive application-oriented college”.

\section{B. Improving the Model of College Governance}

First, in accordance with the relevant laws and policies such as Private Education Promotion Law, colleges need to optimize the leadership decision-making mechanism, and clarify the functional scope and meeting rules for the board of directors and presidents to ensure that the colleges' decisionmaking is democratic, standardized, scientific and efficient. The second is to establish a sound modern college system to realize the legalization of college governance. The third is to enhance the market supervision and the third-party evaluation of independent colleges to ensure the direction and quality of running colleges. In order to accelerate the healthy development of independent colleges, Guangxi Zhuang Autonomous Region has promoted the construction of independent colleges' regulations, the establishment of meeting rules for independent college leadership, and also implemented the annual inspection system of private colleges, which effectively promotes the internal governance of independent colleges and also improves its overall governance of the colleges.

\section{Closely Catering for the Needs of Regional Economic and Social Development}

Independent colleges should focus their own advantages in education and satisfy the personnel demands of the local industry chain. Meanwhile, they should select and develop disciplines and programs that could help promote the local development and focus their own advantages in the construction of featured degree programs. Brand programs with distinctive features should also be established by the means of enhancing personnel training quality and promoting the publicity of these brand programs. Furthermore, differentiation college-running strategy should be adopted in order to avoid and reduce the competition for resources with those traditional undergraduate universities and colleges in the same region. For independent colleges, further expanding and development means that they should optimize the structure of their disciplines and programs, find out the weakness of local higher education, and develop vocational education. Taking Lushan College of Guangxi University of Science and Technology as an example, since Liuzhou city, where the college is located, is a vigorous industrial city with automobile and mechanical as its two pillar industries, the college develops its two major groups suitable for automobile and mechanical industry chain according to the needs of local development, successfully shaping majors with high quality and obvious features in the province.

\section{Implementing Talent-based Development Strategy}

For independent colleges, excellent faculty resource is the premise for further and fast development. Therefore, it is a necessity to recruit high-level talents and to employ teachers who have both expertise and practice within the reach of financial power. Meanwhile, we also create conditions for full-time teachers' development: on the one hand, we strengthen the training of young teachers, helping them to be "Shuangshi" (dual qualified teachers) through the mechanism which allows teachers to work in enterprises for a period of time and get practice experience; on the other hand, we also deepen the combination of industry and teaching, offer technical service for micro-enterprises so as to enhance teachers' capability in both practice and academic research and hereby explore a way in applicative research. In a word, independent colleges should help promote young teachers' 
development through diversified ways and enhance the faculty level as a whole. In the past two years, Lushan College of Guangxi University of Science and Technology adopted talent-based development strategy of integration of recruitment and training, making greater efforts in talents recruitment in spite of the regional disadvantage. With the successive recruitment of 72 professors or teachers with high professional titles, the total number of full-time professors or teachers with high professional titles in Lushan College has reached 159

\section{E. Creating Unique College Cultural Environment}

It is of great significance for independent colleges to create college culture by strengthening humanistic education, innovation and entrepreneurship education and craftsman spirit cultivation. Excellent college culture can help students to form all-around knowledge system and profound humanistic quality, reduce the utilitarian impact on students by application education, and achieve healthy development in cognitive, sentiment and will power. For instance, Lijiang College of Guangxi Normal University has successfully created college culture themed with "the greatest kindness", which is rooted in the college features.

\section{CONCLUSION}

A SWOT analysis of the characteristic independent college-running path gives us a clear and all-around picture of their present status and future development, which helps to propose an objective and concrete strategy for their characteristic college-running. Currently, the development of independent colleges has entered a new era, in which serving the regional economic and social development has been the main trend for independent colleges. Therefore, in order to realize the long-term development, it is a necessity for independent colleges to develop with distinctive features and high quality, which depend on the following elements: the guidance of national policy, the promotion of acceptance and recognition from society, and the connotative improvement in college-running orientation, college management, program construction, faculty cultivation, and college culture construction. All in all, the distinctive development for independent colleges is a systematic program. Only after we have known the exact present status of independent colleges, the truth in its development and found out a development strategy with its own characteristics, can it achieve greater accomplishment as a private component in our higher education system.

\section{REFERENCES}

[1] Wang Fuwei. "The dilemma of institutionalization of independent college: policy change shaped by multiple institutional logics,” Beijing: Peking University Education Review, Vol. 10, No. 2, 2012, PP. 7996+189-190, April 2012.

[2] Fei Jian. “A strategic study on independent colleges development in China” Nanjing: Journal of Nanjing Agricultural University, 2012. (In Chinese)

[3] Luo Xiaoqing \& Fan Ming. "The logical rationality and practical orientation of the transformation and development of independent colleges: the research based on the combination analysis model of "K-S," Beijing: Journal of Higher Education Management, VoL.9, 2018, PP.5461, September 2018. (In Chinese)

[4] Zeng Caihua. "A study on feature running of independent colleges," Jinzhou: Journal of Yangtze University (Social Sciences Edition), 2018. (In Chinese)

[5] Yuanke. "Exploring the strategy of independent college transfer in the perspective of stakeholders," Shanxi: Theoretical Exploration, No. 5, 2018, PP. 85-94. (In Chinese)

[6] Que Ming-kun. "Challenges Faced and Strategies Applicable in Transition from Private Universities to Universities of Applied Sciences: An Empirical Study Based on Survey of 141 Private Universities Nationwide," Shanghai: Fudan Education Forum, VoL.14, 2016, PP.7985, February 2016. (In Chinese)

[7] Yu Zhenghong, WEI Yuanyuan, HU Chun, “Analysis of the Main Competitors and Development Direction of Non-governmental Undergraduate University," Hangzhou: Journal of Zhejiang Shuren University (Humanities and Social Sciences), VoL.14, 2014, PP.21-26, June 2014. (In Chinese) 